\title{
Evaluation of modified stainless steel surfaces targeted to reduce biofilm formation by common milk sporeformers
}

\author{
Shivali Jindal, ${ }^{*}$ Sanjeev Anand, ${ }^{* 1}$ Kang Huang, $\dagger$ Julie Goddard, $\dagger^{2}$ Lloyd Metzger, ${ }^{*}$ \\ and Jayendra Amamcharlał \\ *Midwest Dairy Foods Research Center, Dairy Science Department, South Dakota State University, Brookings 57007 \\ †Department of Food Science, University of Massachusetts, Amherst 01002 \\ ¥Animal Sciences and Industry, Kansas State University, Manhattan 66506
}

\begin{abstract}
The development of bacterial biofilms on stainless steel (SS) surfaces poses a great threat to the quality of milk and other dairy products as the biofilm-embedded bacteria can survive thermal processing. Established biofilms offer cleaning challenges because they are resistant to most of the regular cleaning protocols. Sporeforming thermoduric organisms entrapped within biofilm matrix can also form heat-resistant spores, and may result in a long-term persistent contamination. The main objective of this study was to evaluate the efficacy of different nonfouling coatings [AMC 18 (Advanced Materials Components Express, Lemont, PA), Dursan (SilcoTek Corporation, Bellefonte, PA), Ni-P-polytetrafluoroethylene (PTFE, Avtec Finishing Systems, New Hope, MN), and Lectrofluor 641 (General Magnaplate Corporation, Linden, NJ)] on SS plate heat exchanger surfaces, to resist the formation of bacterial biofilms. It was hypothesized that modified SS surfaces would promote a lesser amount of deposit buildup and bacterial adhesion as compared with the native SS surface. Vegetative cells of aerobic sporeformers, Geobacillus stearothermophilus (ATCC 15952), Bacillus licheniformis (ATCC 6634), and Bacillus sporothermodurans (DSM 10599), were used to study biofilm development on the modified and native SS surfaces. The adherence of these organisms, though influenced by surface energy and hydrophobicity, exhibited no apparent relation with surface roughness. The Ni-P-PTFE coating exhibited the least bacterial attachment and milk solid deposition, and hence, was the most resistant to biofilm formation. Scanning electron microscopy, which was used to visualize the extent of biofilm formation on
\end{abstract}

\footnotetext{
Received May 3, 2016.

Accepted August 16, 2016.

${ }^{1}$ Corresponding author: sanjeev.anand@sdstate.edu

${ }^{2}$ Current address: Department of Food Science, Cornell University, Ithaca, NY 14853.
}

modified and native SS surfaces, also revealed lower bacterial attachment on the Ni-P-PTFE as compared with the native SS surface. This study thus provides evidence of reduced biofilm formation on the modified SS surfaces.

Key words: nickel-phosphorus-polytetrafluoroethylene, biofilm, sporeformer, coating

\section{INTRODUCTION}

Heat-resistant spore formers in milk present a significant challenge to product quality and safety due to their ability to survive thermal processing treatments. These bacteria are known to colonize in large numbers during the long processing runs and develop cleaning-resistant biofilms (Lücking et al., 2013), enabling cross-contamination of finished products. The plate heat exchangers (PHE) that are commonly used for pasteurizing milk are fabricated out of stainless steel SS316. As milk flows through the PHE, the proteins undergo thermal denaturation and foul on its surface, accelerating bacterial attachment. According to Rosmaninho and Melo (2006), even whey proteins present in milk, especially $\beta-\mathrm{LG}$, denature and aggregate upon heating, which is responsible for fouling on the surface of PHE. Also, calcium phosphate, formed as a result of precipitation of calcium and phosphate ions, deposits minerals on the surface of PHE, and hence further contributes to fouling. It was reported by Hinton et al. (2002) that more bacterial activity was observed on the fouled surface, to a level of $10^{5} \mathrm{cfu} / \mathrm{cm}^{2}$, as compared with the unfouled surface. Food residues further protect microorganisms within biofilms, which makes them more resistant to regular cleaning protocols. Once the biofilms are formed on equipment surfaces, they also lead to resistance in heat transfer, and it was reported that even $0.05-\mathrm{mm}-$ deep biofilm can decrease the heat transfer by one-third (Sandu and Singh, 1991). It has further been reported that metal surfaces even get corroded (Bryers, 1987) due to the presence of biofilms and the metabolic activ- 
Table 1. Identification of native stainless steel (SS) surface and 4 commercial coating technologies evaluated in this work

\begin{tabular}{|c|c|c|}
\hline $\begin{array}{l}\text { Coating } \\
\text { abbreviation }\end{array}$ & Description & Manufacturer \\
\hline Lectrofluor 641 & Fluoro polymer-based coating on SS & General Magnaplate Corporation, Linden, NJ \\
\hline AMC 18 & Anti-stiction coating available commercially & Advanced Materials Components Express, Lemont, PA \\
\hline Dursan & $\begin{array}{l}\text { Composed of carboxy silicon material inter-diffused } \\
\text { with SS }\end{array}$ & SilcoTek Corporation, Bellefonte, PA \\
\hline
\end{tabular}

${ }^{1} \mathrm{PTFE}=$ polytetrafluoroethylene.

ity of the microorganisms present inside the biofilms. This results in major costs for repair and replacement of equipment. Thus, a significant opportunity is present to improve the safety, quality, and operating efficiency of dairy processing operations by reducing fouling and biofilm formation on PHE.

The likelihood of biofouling by proteins, mineral deposits, and thermoduric bacteria depends on the surface properties of PHE, such as surface energy, surface roughness, and hydrophobicity. It was reported by Liu et al. (1997) that fouling was higher for surfaces having greater surface energy. Studies were also conducted to link surface energy to cell adhesion; however, none of the theories provide conclusive evidence. Tsibouklis et al. (2000) supported the use of low surface energy to inhibit bacterial adhesion, whereas Zhao (2004) presented a case for an optimum value of surface energy $(30 \mathrm{~N} / \mathrm{m})$ for which bacterial adhesion could be minimized. Similarly, reports conflict regarding the influence of surface roughness on bacterial adhesion and biofilm formation on the surface of PHE. Some researchers reported that bacterial adhesion increases with the increasing surface roughness (Masurovsky and Jordan, 1958; Hoffman, 1983; Pedersen, 1990). On the other hand, other researchers believe that no correlation is present between surface irregularities and the ability of bacteria to attach (Langeveld et al., 1972; Vanhaecke et al., 1990). This may be due to differences in degree of physico-chemical parameters of the surface studied, the bacterial species tested, the bulk fluid phase under study, and the method used to detect bacterial adhesion (Flint et al., 2000).

We have previously reported on an electroless nickel coating process in which fluoropolymer particles (polytetrafluoroethylene, PTFE) are codeposited in a nickel phosphorus coating on 316SS, resulting in a coating that is resistant to both protein and mineral fouling during dairy processing, bacterial adhesion, and biofilm formation by Bacillus cereus (Barish and Goddard, 2013). Our results were promising, yet the coatings were prepared on a laboratory scale, limiting the commercial translatability of the technology. An opportunity remains for demonstrating the efficacy of commercially scalable techniques in surface modification of SS316.

The main focus of the current research was to evaluate the 4 commercially available surface modifications of SS316, so as to select the coated surface that is most resistant to adhesion and biofilm formation by thermoduric sporeformers. The 4 surface modifications, listed in Table 1, were also evaluated for differences in their surface energy, surface roughness, and hydrophobicity. Scanning electron microscopy technique was used to image the native and modified surfaces for visually comparing the biofilm formation.

\section{MATERIALS AND METHODS}

\section{Source of Native and Modified SS Coupons}

Actual corrugated SS heat exchanger plates were cut into SS316 (0.0254 m × $0.0254 \mathrm{~m}, 0.0005 \mathrm{~m}$ thick $)$ coupons to mimic the surface of PHE. These were donated by AGC Heat Transfer (Portland, OR), and used as SS surface control or modified using the 4 commercial coating technologies as listed in Table 1. Each coating was applied on 12 corrugated and 12 flat SS coupons using a spin coating or dip coating method. Corrugated coupons were used for microbiological analysis and the flat coupons were used for surface characterization. For coating purposes, the AMC 18 was supplied by AMCX (Tyrone, PA) and is commercially available. The Dursan is composed of carboxy silicon material, inter-diffused with the SS substrate, resulting in a 0.0000004- to 0.0000016-m coating, and was supplied by SilcoTek Corporation (Bellefonte, PA). The Lectrofluor 641 is a fluoro polymer-based coating and was supplied by General Lectrofluor 641 Corporation (Linden, NJ). The Ni-P-PTFE coatings were prepared by a previously reported method (Barish and Goddard, 2013 ) in which approximately $0.00000762 \mathrm{~m}$ of nickel is coated by electroless deposition onto cleaned, Wood's 
Table 2. Test isolates, their source, and growth temperature

\begin{tabular}{llc}
\hline Organism & Source & Optimum growth temperature $\left({ }^{\circ} \mathrm{C}\right)$ \\
\hline Geobacillus stearothermophilus & ATCC 15952 & 50 \\
Bacillus licheniformis & ATCC 6634 & 30 \\
Bacillus sporothermodurans & DSM 10599 & 30 \\
\hline
\end{tabular}

strike SS316, followed by codeposition of PTFE particles $(\sim 0.0000002 \mathrm{~m}$ diameter $)$ in a second electroless nickel deposition step.

\section{Surface Characterization of Native and Modified SS316}

Dynamic Contact Angle. Kruss DSA 100 Drop Shape Analyzer (Hamburg, Germany) was used to measure the contact angle of HPLC water on the native and modified SS surface (Schmidt et al., 2004). Contact angle fitting method from the Drop Shape Analysis software version 1.91.0.2 was used for the measurement. A steady temperature of $25 \pm 1^{\circ} \mathrm{C}$ was maintained while taking all the measurements. While taking the measurements, a single drop of water $(5 \mu \mathrm{L})$ flowing at $25 \mu \mathrm{L} / \mathrm{min}$ was credited on the SS surface. A total of 9 scans were performed (3 measurements on each of 3 independent samples) for every treatment.

Surface Energy. Surface energy was quantified with the help of a Neumann model by using the advancing values of 4 test liquids with known surface tension: HPLC water $(72.8 \mathrm{mN} / \mathrm{m})$, glycerol $(64 \mathrm{mN} / \mathrm{m})$, formamide $(58 \mathrm{mN} / \mathrm{m})$, and ethylene glycol $(48 \mathrm{mN} / \mathrm{m})$. The relationship between the advancing value and the surface tension of 4 liquids was fitted with the Neumann model. The critical surface tension of the test surface was calculated when $\cos \theta=1$. The Neumann model was shown as below:

$$
\cos \theta=-1+2 \sqrt{\frac{\gamma_{S V}}{\gamma_{L V}}} e^{-\beta\left(\gamma_{L V}-\gamma_{S V}\right)^{2}}
$$

where $\theta$ is the contact angle (degree), $\gamma_{L V}$ is the surface energy of the liquid $(\mathrm{mN} / \mathrm{m}), \gamma_{S V}$ is the surface energy of the solid $(\mathrm{mN} / \mathrm{m})$, and $\beta$ is the constant $\left(\mathrm{m}^{2} / \mathrm{mN}^{2}\right)$, respectively.

Surface Roughness. Roughness of different modified surfaces was determined using optical profilometry that was carried out on Zeta-20 optical profilometer (Barish and Goddard, 2014). A 20× camera lens (WD $=3.10 \mathrm{~mm}$ ) was used with a total scanning area of $1,173 \times 880 \mu^{2}$. The 3D Zdot software (Zeta Instruments, San Jose, CA) was employed to examine the images. Native and modified SS coupons were compared for their surface roughness. The results were reported as an average \pm standard error for a total of 9 scans $(3$ analyses on each of 3 independently prepared coupons).

\section{Bacterial Biofilm Formation on Native and Modified SS Coupons}

Sourcing and Maintaining Bacterial Isolates. Biofilm formation-related studies were performed using 3 different aerobic spore-forming bacteria, namely Geobacillus stearothermophilus (ATCC 15952), Bacillus licheniformis (ATCC 6634), and Bacillus sporothermodurans (DSM 10599). Reference strains of these aerobic spore-forming bacteria were obtained from the American Type Culture Collection (ATCC, Manassas, VA) and Deutsche Sammlung von Mikroorganisem und Zellkulturen (DSM), Germany. The bacterial strains were grown in freshly prepared Brain Heart Infusion (BHI) Broth (Oxoid, Thermo Scientific, UK) by incubating at their optimum growth temperatures (Table 2) as recommended by ATCC and DSM, and were preserved for future use in cryogenic vials (Perry, 1995).

Each activated culture was centrifuged at $4,500 \times g$ for 30 min at $4^{\circ} \mathrm{C}$ using Avanti JE centrifuge (Beckman Coulter Inc.). The pellets thus obtained were subsequently suspended in PBS at $\mathrm{pH} 7.4$ and maintained in 1.8-mL cryogenic vials (Copan Diagnostic Inc., Murrieta, CA) that contained sterile beads and glycerol. The vials were stored in a NuAire ultralow deep freezer (NuAire Inc., Plymouth, MN) at $-80^{\circ} \mathrm{C}$ until further use (Khanal et al., 2014).

Preparation of Vegetative Cell Suspensions. Vegetative cells of the respective organisms were prepared by transferring the culture from cryo-vials in to BHI broth and incubating at their optimum growth temperature in a shaking incubator (at $150 \mathrm{rpm}$ ). After overnight incubation, vegetative cells were harvested by centrifugation at $4,500 \times g$ for $10 \mathrm{~min}$ at $4^{\circ} \mathrm{C}$. The pellets obtained were washed in PBS and adjusted to a concentration of $\log 7.0 \mathrm{cfu} \cdot \mathrm{mL}^{-1}$, and were then used for spiking the growth medium for biofilm formation studies on coated coupons.

Development of Biofilms on Native and Modified SS Coupon. Three trials, with 2 coupons each, were conducted for each experiment. Before initiating the experiment, native and 4 types of modified SS coupons were washed with deionized water, followed 
by washing with $70 \%$ alcohol, and rinsing the coupons with de-ionized water, which were then sterilized by autoclaving at $121^{\circ} \mathrm{C}$ for $15 \mathrm{~min}$. Two coupons of each type were separately submerged in Petri dishes containing $25 \mathrm{~mL}$ each of $11 \%$ total solids sterile reconstituted nonfat dry milk (NFDM). The NFDM was chosen as a growth medium as the fat interacts with the hydrophilic surface of SS surface (Barnes et al., 1999). Overnight grown culture of $G$. stearothermophilus was spiked into reconstituted NFDM in the Petri dish to a level of around $\log 6.0 \mathrm{cfu} \cdot \mathrm{mL}^{-1}$. These Petri dishes (having milk inoculated with the organism, and SS316 native and modified coupons) were incubated at $50^{\circ} \mathrm{C}$ (being the optimum growth temperature and also the temperature encountered in regeneration section of PHE) with the purpose of forming biofilms on the surface of coupons. Zero hour counts of milk were taken right after inoculation of bacteria, to ascertain the actual initial counts of culture (initial level of spiking) being inoculated in to growth medium (sterile reconstituted NFDM). The growth medium was replaced every $15 \mathrm{~h}$, without causing any disturbance to the biofilms already formed on the coupons. This was done to provide fresh nutrients to the bacteria and also to remove toxic substances and acids being generated in the growth medium as a result of bacterial metabolism. This process was continued for $72 \mathrm{~h}$. As the preliminary experiments to evaluate the formation of G. stearothermophilus biofilms indicated that the Ni-P-PTFE modified SS316 was the most resistant to biofilms; therefore, the Ni-P-PTFE coupons were further evaluated for biofilm development using the other 2 cultures: B. licheniformis (ATCC 6634) and B. sporothermodurans (DSM 10599).

Development of Mixed Species Biofilm on Native and Modified SS Coupons. The biofilm formation was also studied on native SS surface and modified SS surface (Ni-P-PTFE) using a mixed culture of $B$. licheniformis and G. stearothermophilus following the same protocol as described above.

Enumeration of Viable Cells Embedded Within Biofilm Matrix. At the end of $72 \mathrm{~h}$ incubation, the coupons immersed in bacterial growth medium were removed from the Petri dish using sterile tweezers, and rinsed with phosphate buffer to remove nonadherent and loosely adhered cells. This was followed by swabbing the targeted area $\left(6.25 \mathrm{~cm}^{2}\right)$ using sterile $3 \mathrm{M}$ Quick swabs (3M, St. Paul, MN). The swab tube was vortexed for $10 \mathrm{~s}$ to release all cells from the swab tip. Swab tip was pressed and twisted against the wall of swab tube to facilitate the recovery of all bacterial cells. The contents in the tube were then mixed and serially diluted in sterile PBS solution at $\mathrm{pH}$ 7.4. Aerobic plate counts were performed on BHI agar plates (Khanal et al., 2014) using spread plate technique (Downes and
Ito, 2001). The plates were incubated for 24 to $48 \mathrm{~h}$ at $50^{\circ} \mathrm{C}$. The colony-forming units were calculated and the counts were reported as $\log \mathrm{cfu} / \mathrm{cm}^{2}$ (Wehr and Frank, 2004)

Microscopic Visualization of Bacterial Biofilms. The electron micrographs, for studying the microstructure of matured biofilms formed on different surfaces, were obtained using a scanning electron microscope (Hitachi S-3400N, Hitachi America Ltd., Tarrytown, NY), located in the Daktronics Engineering Hall, South Dakota State University. The air drying method (Hassan et al., 2010), with slight modifications involving a reduction in air drying time, was used to fix the biofilm on the coupon surface with minimum structural damage and to obtain a partially dehydrated biofilm for electron microscopy. Samples were air-dried for $12 \mathrm{~h}$ after moderate rinsing with phosphate buffer (pH 7.0) at room temperature under laminar airflow, followed by sputter coating with a 10-nm-thick layer of deposition of $99 \%$ gold. Biofilms were then observed under the scanning electron microscope at $10 \mathrm{kV}$ accelerating voltage by maintaining a distance of $10 \mathrm{~mm}$ from the coupon.

\section{Statistical Analysis}

Trials were repeated thrice with 2 replicates in each experiment. The bacterial counts were calculated for mean values and standard error. Means were compared using Tukey multiple comparison test using SAS 9.3 software (SAS Institute Inc., Cary, NC) with least significance difference at $P<0.05$. The surface properties such as surface energy, surface roughness, and hydrophobicity were correlated with the various SS modifications using Microsoft Excel (Microsoft Corp., Redmond, WA).

\section{RESULTS AND DISCUSSION}

\section{Effects of Surface Properties on Formation of Bacterial Biofilms}

Biofilm formation on the food contact surface involves the events of milk solid deposition, bacterial adhesion and colonization, and finally the biofilm formation. A deep insight into the surface properties of various coated surfaces and their relationship with the extent of bacterial adhesion is essential to minimize the biofilm formation. The surface properties of various modified surfaces were investigated in terms of surface energy, surface roughness, and hydrophobicity.

Surface Energy of Coated Surfaces. Surface energy is defined as the extent of attractive or repulsive force that a material surface exerts on another surface. 


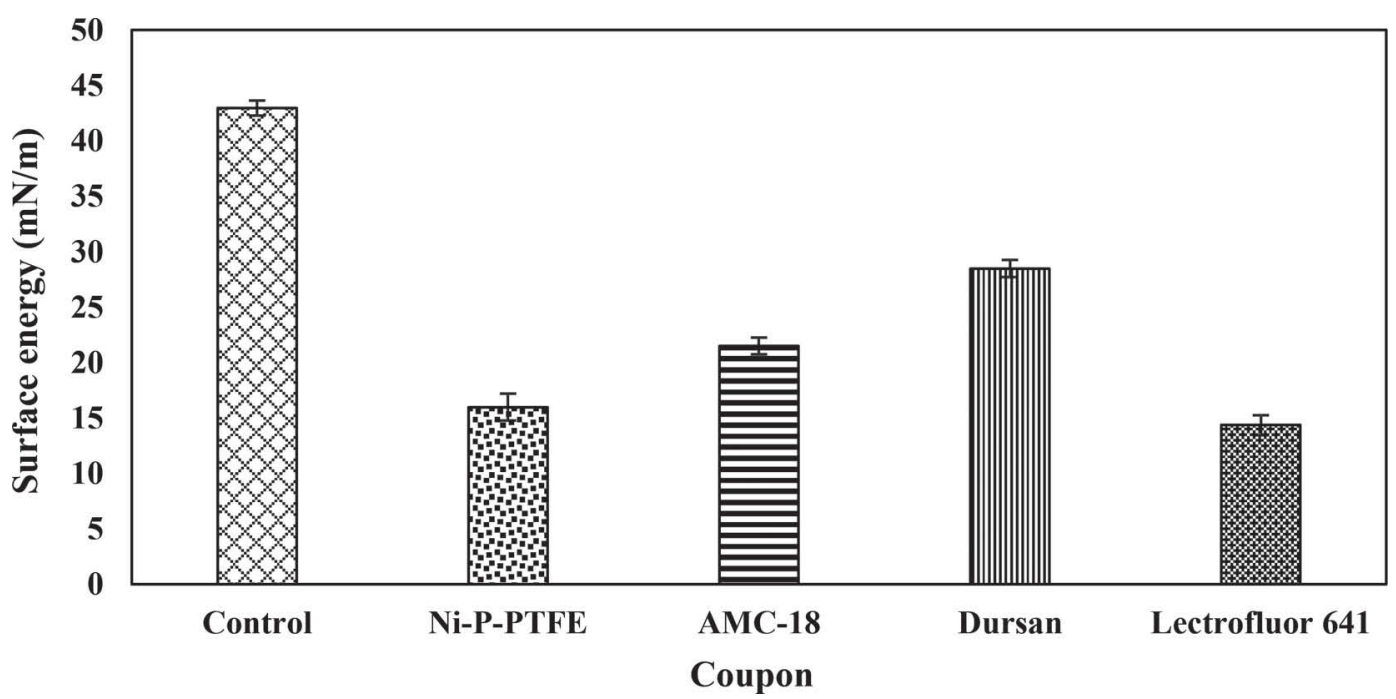

Figure 1. Surface energy of native and modified 316 stainless steel coupons. Values are an average of 3 independent samples \pm SE. Ni-PPTFE $=$ Ni-P-polytetrafluoroethylene, Avtec Finishing Systems, New Hope, MN; AMC-18, Advanced Materials Components Express, Lemont, PA; Dursan, SilcoTek Corporation, Bellefonte, PA; Lectrofluor 641, General Magnaplate Corporation, Linden, NJ.

In the context of this experiment, it is the extra energy required to detach the bacteria that are in contact with the fouled surface. With the reduction in surface energy, the binding energy between the surface and bacteria attached to it could be lowered and further could lead to an increase in the detachment tendency of the attached bacteria. Consequently, the biofilm formation can thus be minimized (Dexter, 1979). Experimental results obtained in our study also supports the above study, suggesting a decrease in the extent of bacterial attachment with the descent of surface energy (Figure 1) of native and modified SS surfaces. Native SS surface with the highest value of surface energy $(42.94 \pm 0.67 \mathrm{mN} / \mathrm{m})$ recorded maximum bacterial attachment $(\log 5.11 \pm$ $0.03)$ to its surface. On the other hand, Ni-P-PTFE and Lectrofluor 641 with comparable lower values of surface energies $(15.96 \pm 1.21 \mathrm{mN} / \mathrm{m}$ and $14.34 \mathrm{mN} / \mathrm{m}$, respectively), also recorded lower bacterial adhesion (3.15 \pm 0.04 and $3.42 \pm 0.04 \log _{10} \mathrm{cfu} / \mathrm{cm}^{2}$, respectively; Table 3). Similarly, the other 2 modified SS surfaces (AMC 18, Dursan) with lower values of surface energies than native SS also showed less bacterial adhesion to their surfaces. With the lowering values of surface energies for different modified SS surfaces (AMC 18, Dursan), the extent of bacterial attachment to the respective surfaces also decreased. Some studies have previously been conducted by other researchers to investigate the effect of surface energy on the extent of bacterial adhesion on the surface. A study conducted by Baier (2006) showed an optimum value $(20-30 \mathrm{mN} / \mathrm{m})$ of surface energy for which bacterial adhesion is at a minimum. The bacterial adhesion would thus be greater for surface energies more or less than the optimum value. The possible reason proposed by them for this typical attachment behavior is the influence of bacterial properties (cell surface hydrophobicity and zeta potential), which alter their attachment to the SS surface, resulting in minimal attachment at optimal value of surface energy. Another study conducted by Rönner et al. (1990) also indicated that greater the absolute charge on the cell wall of bacteria, the less will be its tendency to adhere to the surface.

Surface Roughness of Coated Surfaces. Surface roughness is the deviation of the vector perpendicular to the real surface from ideal direction. If the angle of deviations is large, the surface is said to be rough or else if the deviations are trivial, the surface is said to be smooth. In general, it is expected and seems obvious that more bacteria should attach on a rough surface as a result of bacterial entrapment (Hoffman, 1983; Pedersen, 1990). However, other studies suggest that there may not be a correlation between the surface irregularities and bacterial adhesion (Langeveld et al., 1972; Mafu et al., 1990; Tide et al., 1999).

Figures 2A, 2B, 2C, 2D, and 2E show the optical profilometry images acquired from the Zeta-20 optical profilometer, which relates to surface roughness of native and modified SS surface and is further qualified from the average surface roughness values of different SS surfaces (Figure 3). According to the results of the experiments conducted, Lectrofluor 641 with the greatest surface roughness $(2.64 \mu \mathrm{m})$ and Ni-P-PTFE with 
Table 3. Viable counts in biofilms of Geobacillus stearothermophilus formed on native and modified stainless steel (SS) surface

\begin{tabular}{|c|c|c|c|c|c|}
\hline \multirow[b]{2}{*}{ Item } & \multicolumn{5}{|c|}{ Type of coupon ${ }^{1}$} \\
\hline & SS316 & AMC 18 & Lectrofluor 641 & Dursan & Ni-P-PTFE ${ }^{2}$ \\
\hline Average count ${ }^{3}\left(\log _{10} \mathrm{cfu} / \mathrm{cm}^{2}\right)$ & $5.11 \pm 0.03^{\mathrm{a}}$ & $3.89 \pm 0.04^{\mathrm{c}}$ & $3.42 \pm 0.04^{\mathrm{d}}$ & $4.40 \pm 0.02^{\mathrm{b}}$ & $3.15 \pm 0.04^{\mathrm{e}}$ \\
\hline $\begin{array}{l}{ }^{\mathrm{a} e} \text { Values with different lowerca } \\
{ }^{1} \text { SS316 (AGC Heat Transfer, Po } \\
\text { Lectrofluor } 641 \text { (General Magr } \\
\text { PA), Ni-P-PTFE (Avtec Finish } \\
{ }^{2} \mathrm{PTFE}=\text { polytetrafluoroethyle } \\
{ }^{3} \mathrm{Mean} \pm \text { SE. }\end{array}$ & $\begin{array}{l}\text { superscript le } \\
\text { land, OR), AN } \\
\text { plate Corpora } \\
\text { g Systems, Ne }\end{array}$ & $\begin{array}{l}\text { ters within a } \mathrm{r} \\
\mathrm{C} 18 \text { (Advance } \\
\text { ion, Linden, N } \\
\text { N Hope, MN). }\end{array}$ & $\begin{array}{l}\text { Ww are significant } \\
\text { d Materials Comp } \\
\text { J), Dursan (Silcc }\end{array}$ & $\begin{array}{l}\text { y different at } \\
\text { onents Expres } \\
\text { Tek Corporat }\end{array}$ & $\begin{array}{l}P \text {-value }<0.05 \\
\text { s, Lemont, PA) } \\
\text { ion, Bellefonte }\end{array}$ \\
\hline
\end{tabular}

the least surface roughness $(1.06 \mu \mathrm{m})$ shared almost similar extent of bacterial adhesion (Table 3). This suggests that there may not be a clear relationship between surface texture and the extent of bacterial adhesion. The complexity of the surface and microbial interactions thus makes it impossible to predict biofilm formation based on any single factor (e.g., roughness, surface energy, and bacterial species) alone.

Hydrophobicity of Coated Surfaces. Dynamic contact angle can be used to quantify hydrophobicity or wettability of a surface. If the contact angle is less than $90^{\circ}$, the solid surface is considered to be hydrophilic, resulting in the spreading of liquid on the surface of solid. On the other hand, if the contact angle is greater than $90^{\circ}$, the solid surface is said to be hydrophobic (Bhushan and Jung, 2007).

According to the results achieved for the dynamic contact angle and bacterial adhesion, it is found that native SS, being the least hydrophobic (Figure 4), was the one exhibiting the highest bacterial adhesion. Lectrofluor 641 and Ni-P-PTFE, being the most hydrophobic (Figure 4), demonstrated the least bacterial attachment to their surface (Table 3). Consequently, it can be inferred that with the increase in hydrophobicity of the SS surfaces, the extent of bacterial adhesion declines. Some previous researchers have also reported similar results with hydrophobic surfaces (Fletcher and Loeb, 1979; Pringle and Fletcher, 1983).

In summation, both surface energy and hydrophobicity were found to have a significant role in the bacterial adhesion. Surface energy was observed to be directly related to the adhesion tendency of bacteria, reflecting that the bacterial tendency to attach to the contact surface increases with the surface energy. On the contrary, the hydrophobic character of the coated surface exhibited an inverse relationship with the bacterial adhesion. Surface roughness showed almost no role in influencing the tendency of bacteria to attach to various coated surfaces.

\section{Comparison of Biofilm Development by Different Sporeformers}

Development of biofilms on the surface of native and modified SS coupons by common thermoduric sporeformers was studied at $50^{\circ} \mathrm{C}$ to obtain a biofouling behavior at a temperature similar to that encountered in the regeneration section of PHE. Moreover, this was also the optimum growth temperature for G. stearothermophilus (ATCC 15952). Both B. licheniformis (ATCC 6634) and B. sporothermodurans (DSM 10599) strains used in this study also showed good growth at $50^{\circ} \mathrm{C}$.

A superior attachment and biofilm forming ability of G. stearothermophilus (ATCC 15952) has been reported previously. Doyle et al. (2015) stated that $G$. stearothermophilus (ATCC 15952) caused long-term persistent contamination of dairy processing lines as they formed biofilm on SS surface of processing equipment. Therefore, in our study, all the coatings were first screened for their resistance to bacterial adhesion and biofilm formation using G. stearothermophilus under static conditions.

The initial counts of $G$. stearothermophilus, after its inoculation in the growth medium, were around $\log 6.0$ $\mathrm{cfu} / \mathrm{mL}$. The biofilm-embedded cells of $G$. stearothermophilus (ATCC 15952) were quantified by swabbing an area of $6.25 \mathrm{~cm}^{2}$ after $72 \mathrm{~h}$ of biofilm formation on native and modified SS coupon surfaces, used in the study. Native SS surface attracted the most bacteria. The bacterial counts after the incubation period of 72 $\mathrm{h}$ for native SS coupons were around $\log 5.1 \mathrm{cfu} / \mathrm{cm}^{2}$, which were significantly higher as compared with the modified surfaces (Table 3). A possible reason could be the lower conditioning of modified surfaces due to a reduced amount of milk solids sticking on its surface as compared with the native SS surface. It was previously reported by Barnes et al. (1999) that the pre-conditioning of the surface with organic molecules accelerated the bacterial attachment. It can thus be inferred that 
as the bacterial adhesion is also influenced by the conditioning of the surface; it could be minimized by modifying the surface such that the milk solid deposition is at a minimum. The effect of modifying SS surface on fouling was studied by (Rosmaninho et al., 2007), who reported that a Ni-P-PTFE surface promoted a lesser amount of deposit buildup and was easiest to clean. In another previous study (Zhao, 2004), surface coatings were reported to hinder the bacterial adhesion by 82 to $97 \%$.

A

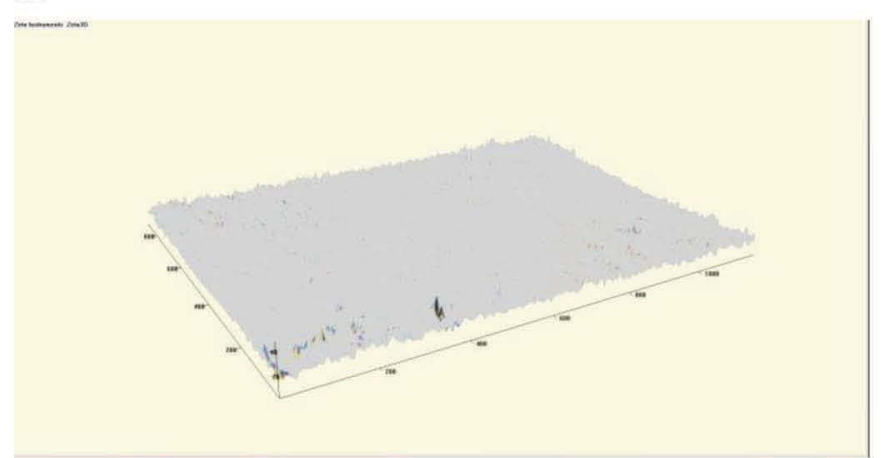

$\mathrm{C}$

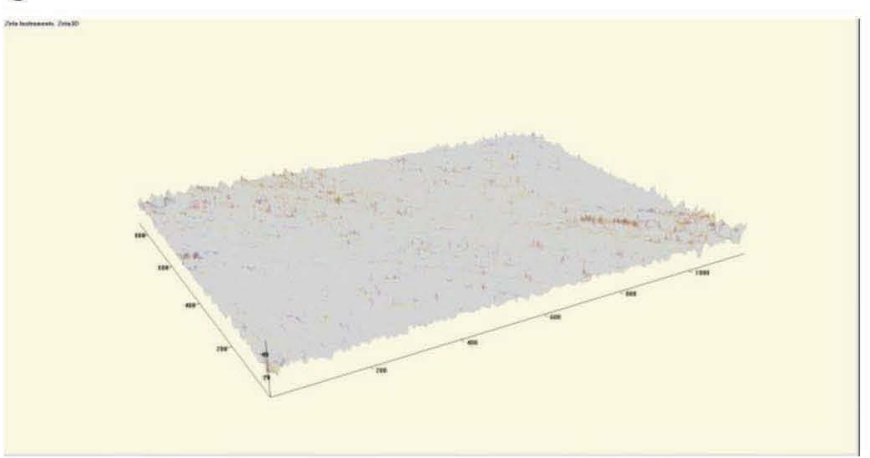

E

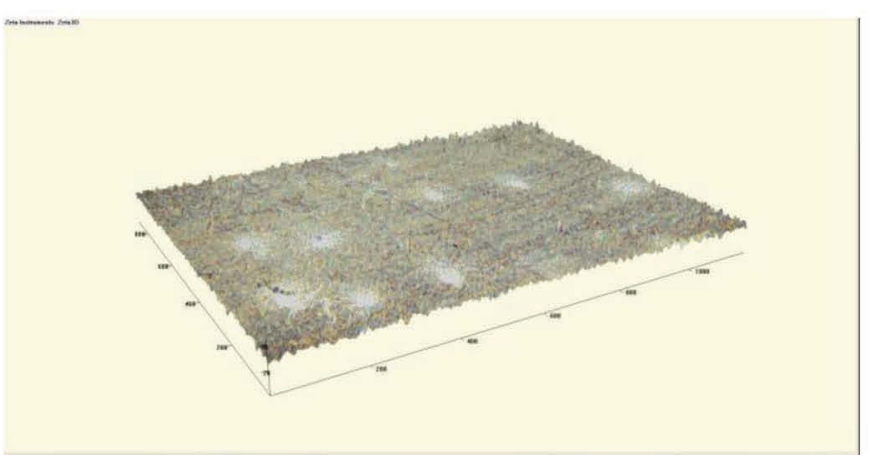

A comparison of the number of adhered cells of $G$. stearothermophilus to different modified and native SS surfaces after $72 \mathrm{~h}$ of incubation revealed that $\mathrm{Ni}$ P-PTFE was most resistant to bacterial attachment, whereas native SS surface recorded a higher bacterial adhesion (Table 3). Similar results were obtained with $B$. licheniformis (Table 4). It was interesting to note that while the biofilm formation trend for B. sporothermodurans was also similar for the 2 surfaces, overall it showed lower biofilm formation on both native

B

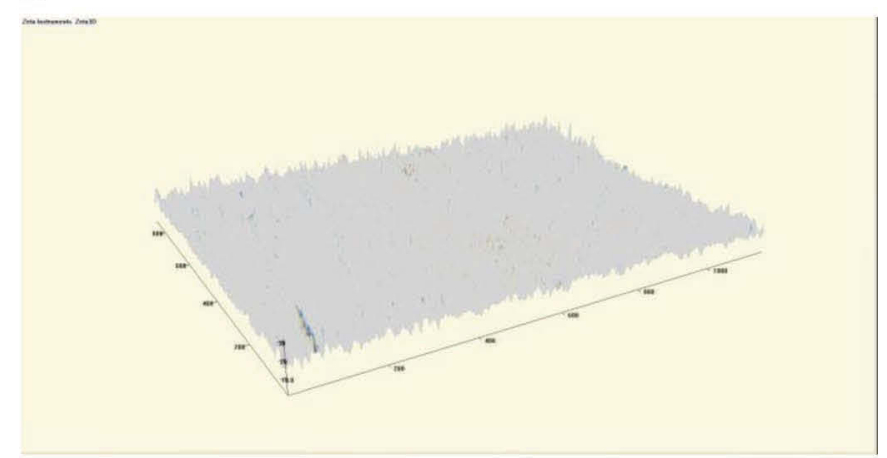

D

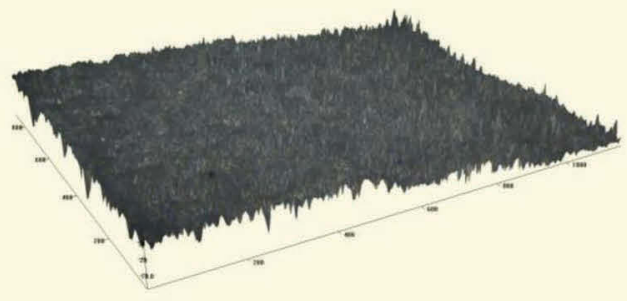

Figure 2. Representative optical profilometer image of (A) a native stainless steel (SS) coupon; (B) modified SS coupon AMC 18 (Advanced Materials Components Express, Lemont, PA); (C) modified SS coupon Dursan (SilcoTek Corporation, Bellefonte, PA); (D) modified SS coupon Lectrofluor 641 (General Magnaplate Corporation, Linden, NJ); (E) modified SS coupon Ni-P-PTFE (Avtec Finishing Systems, New Hope, $\mathrm{MN})$. Color version available online. 


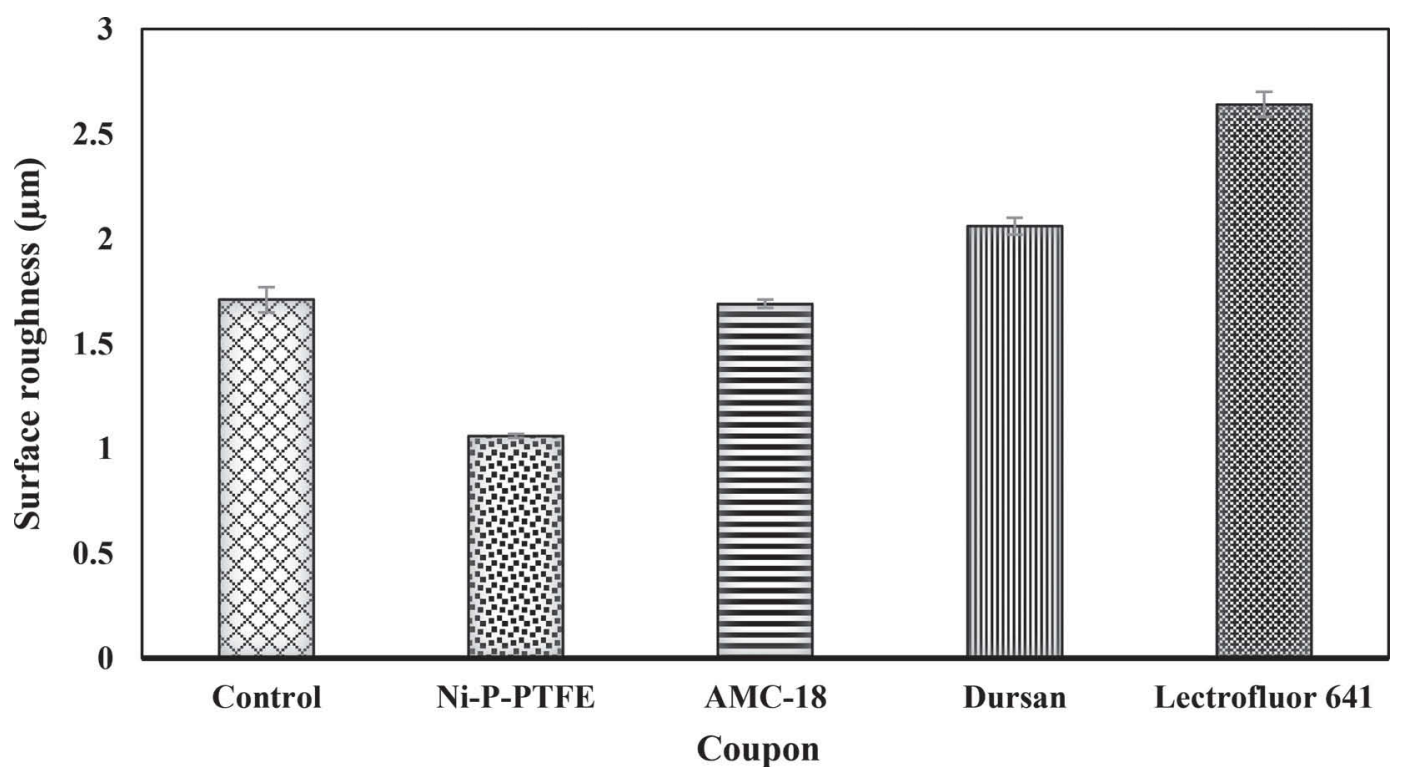

Figure 3. Average surface roughness of native and modified 316 stainless steel coupons. Values are an average of 9 measurements (from 3 distinct regions on 3 independent samples) \pm SE. Ni-P-PTFE $=$ Ni-P-polytetrafluoroethylene, Avtec Finishing Systems, New Hope MN; AMC18, Advanced Materials Components Express, Lemont, PA; Dursan, SilcoTek Corporation, Bellefonte, PA; Lectrofluor 641, General Magnaplate Corporation, Linden, NJ.

and modified surfaces as compared with the other 2 sporeformers. One of the probable reason for this could be the slower multiplication of $B$. sporothermodurans (Klijn et al., 1997). Murphy et al. (1999) also reported that G. stearothermophilus and B. licheniformis exhibited good growth in preheaters and evaporators. To evaluate the biofilm formation by mixed species, the Ni-P-PTFE and native SS coupons were examined for their resistance to a mixed species biofilm consisting of the above 2 aerobic sporeformers. The Ni-P-PTFE exhibited significantly less bacterial attachment as compared with the native SS surface, even for the mixed species biofilms (Table 4).

We also observed that the viable counts in spent growth medium (reconstituted NFDM) at the time of changeovers were always around $7 \mathrm{logs}$, which were

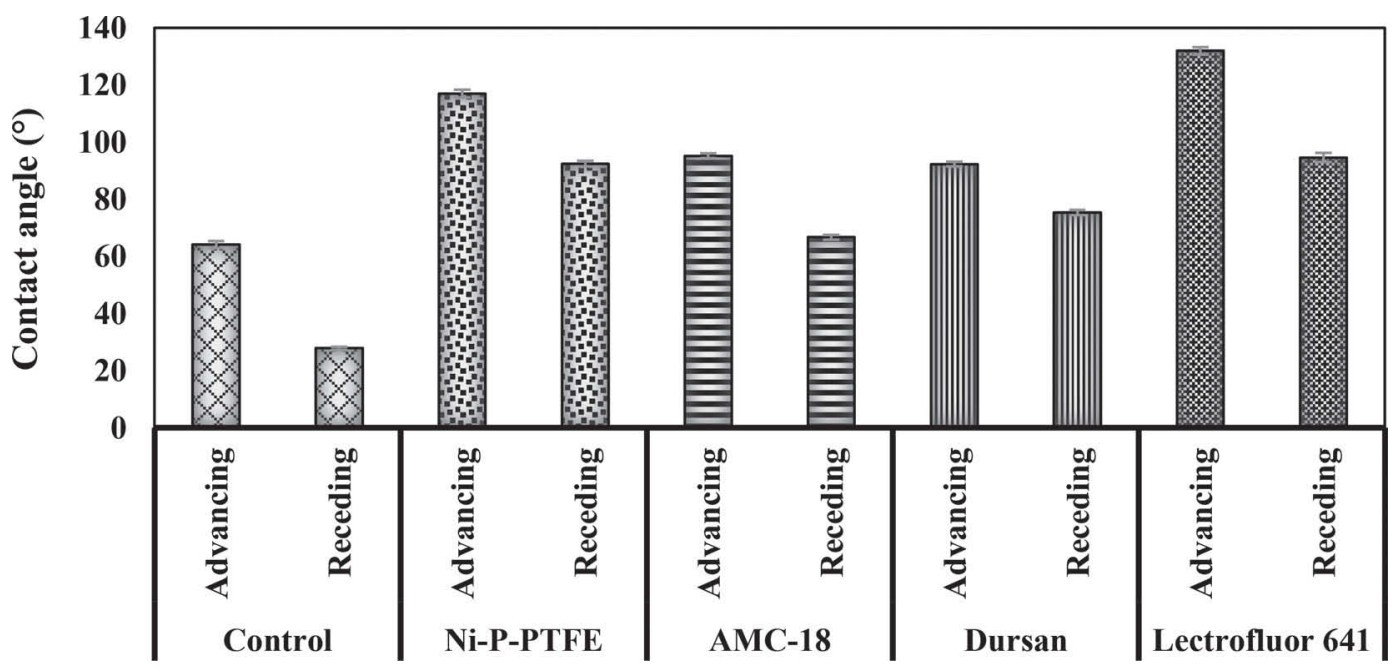

Figure 4. Advancing and receding dynamic contact angle of native and modified 316 stainless steel coupons. Values are an average of 9 scans (from 3 distinct regions on 3 independent samples) \pm SE. Ni-P-PTFE = Ni-P-polytetrafluoroethylene, Avtec Finishing Systems, New Hope, MN; AMC-18, Advanced Materials Components Express, Lemont, PA; Dursan, SilcoTek Corporation, Bellefonte, PA; Lectrofluor 641, General Magnaplate Corporation, Linden, NJ. 
Table 4. Viable counts in biofilms of Geobacillus stearothermophilus, Bacillus licheniformis, Bacillus sporothermodurans, and mixed species (G. stearothermophilus and B. licheniformis) formed on modified [Ni-Ppolytetrafluoroethylene (PTFE)] and native stainless steel (SS) coupons

\begin{tabular}{lcccc}
\hline & \multicolumn{4}{c}{ Average $\operatorname{count}^{2}\left(\log _{10} c f u / \mathrm{cm}^{2}\right)$} \\
\cline { 2 - 5 } Item $^{1}$ & G. stearothermophilus & B. licheniformis & B. sporothermodurans & Multispecies \\
\hline SS316 & $5.10 \pm 0.03^{\mathrm{a}, \mathrm{A}}$ & $5.13 \pm 0.02^{\mathrm{a}, \mathrm{A}}$ & $3.09 \pm 0.02^{\mathrm{b}, \mathrm{A}}$ & $5.09 \pm 0.02^{\mathrm{a}, \mathrm{A}}$ \\
Ni-P-PTFE & $3.15 \pm 0.04^{\mathrm{a}, \mathrm{B}}$ & $3.11 \pm 0.04^{\mathrm{a}, \mathrm{B}}$ & $1.88 \pm 0.06^{\mathrm{b}, \mathrm{B}}$ & $3.09 \pm 0.02^{\mathrm{a}, \mathrm{B}}$ \\
\hline
\end{tabular}

$\overline{a, b}$ Values with difference lowercase superscript letters within a row are significantly different at $P$-value $<0.05$.

${ }^{\mathrm{A}, \mathrm{B}}$ Values with different uppercase superscript letters within a column are significantly different at $P$-value $<$ 0.05 .

${ }^{1}$ SS316 (AGC Heat Transfer, Portland, OR), Ni-P-PTFE (Avtec Finishing Systems, New Hope, MN).

${ }^{2}$ Mean \pm SE.

higher than the biofilm-embedded bacterial counts. Flint et al. (2001) has reported that bacteria entrapped in the biofilm by G. stearothermophilus may also shed in the milk passing over them.

Biofilm Visualization Using Scanning Electron Microscope. A scanning electron microscope was used to examine the microstructures of native and modified SS surfaces, before and after the biofilm formation. From examining the scanning electron micrographs of various modified and native SS surfaces, it is evident that the surfaces were very different visually (Figures $5 \mathrm{~A}, 5 \mathrm{~B}, 5 \mathrm{C}, 5 \mathrm{D}$, and $5 \mathrm{E})$. No particles were seen on Lectrofluor 641, AMC-18, and Dursan, whereas a large number of homogeneously distributed PTFE particles could be seen on the Ni-P-PTFE modified surface. Also, it was observed that the surface of Lectrofluor 641 was extremely rough as compared with the other coatings, which is also evident from the observed results. The micrographs obtained for native as well as modified SS surface after the biofilm formation clearly illustrate that Ni-P-PTFE and Lectrofluor 641 resisted the bacterial attachment and biofilm formation to a greater extent as compared with other surfaces. These 2 surfaces exhibited less bacterial attachment on its surface. On the other hand, the native SS surface demonstrated the greatest microbial adhesion and biofilm formation (Figures 6A, 6B, 6C, 6D, and 6E).

\section{CONCLUSIONS}

The main objective of this study was to evaluate the influence of surface modifications on surface characteristics and biofilm formation by thermoduric sporeformers commonly encountered during dairy processing. Of the several coatings tested, Ni-P-PTFE showed the highest resistance to attachment of bacteria and milk solid deposition, consequently resulting in minimal biofilm formation. The study suggests that SS316 modified with Ni-P-PTFE blend can improve the bacterial inhibiting properties, resulting in lesser biofilm formation.
Therefore, Ni-P-PTFE (most resistant to bacterial biofilm formation) can effectively serve in reducing the bacterial attachment and cross-contamination of dairy products during processing. Surface properties of SS316 also influenced the extent of bacterial adhesion. Less hydrophobic SS surface attracted more bacteria than more hydrophobic surfaces. The Ni-P-PTFE, being the most hydrophobic, demonstrated the least bacterial attachment, clearly indicating that bacterial adhesion decreases with increments in surface hydrophobicity. Bacterial adhesion was also found to decrease with the reduction in surface energy. Native SS surface with the highest value for surface energy also showed maximum bacterial attachment and biofilm formation. In this study, biofilm formation by the tested sporeformers could not be related to the roughness of the surface. The findings from this research provide evidence for the potential of using modified SS surfaces in the dairy and food industry to reduce the biofilm formation, thereby resulting in lower cross-contamination and enhanced microbial quality of end products. The reduced biofilm formation would also help with greater cost effectiveness because of more efficient cleaning operations, saving time, labor, and money.

\section{ACKNOWLEDGMENTS}

This work was financially supported by Dairy Management Inc. (Rosemont, IL) and administered by the Dairy Research Institute (Rosemont, IL). The authors also acknowledge the support of the Agricultural Experimentation Station, South Dakota State University, in conducting this study, and the Electrical Engineering Department, South Dakota State University, for carrying out scanning electron microscope work. AGC Heat Transfer (Portland, OR) is also acknowledged for donating the SS coupons. The results and views expressed in this study by no means promote any one coating over other or for any commercial use. The available coatings were analyzed for their resistance to develop biofilms 
A

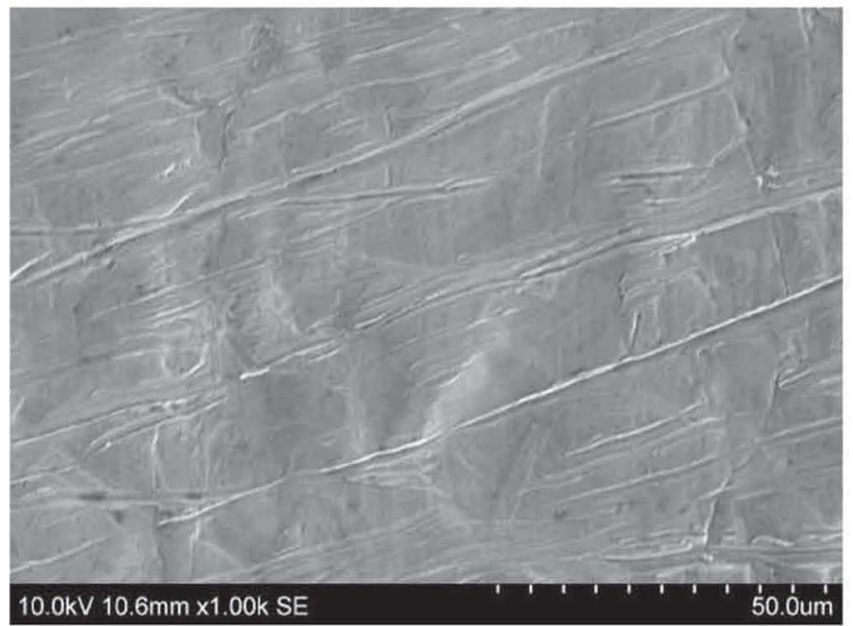

$\mathrm{C}$

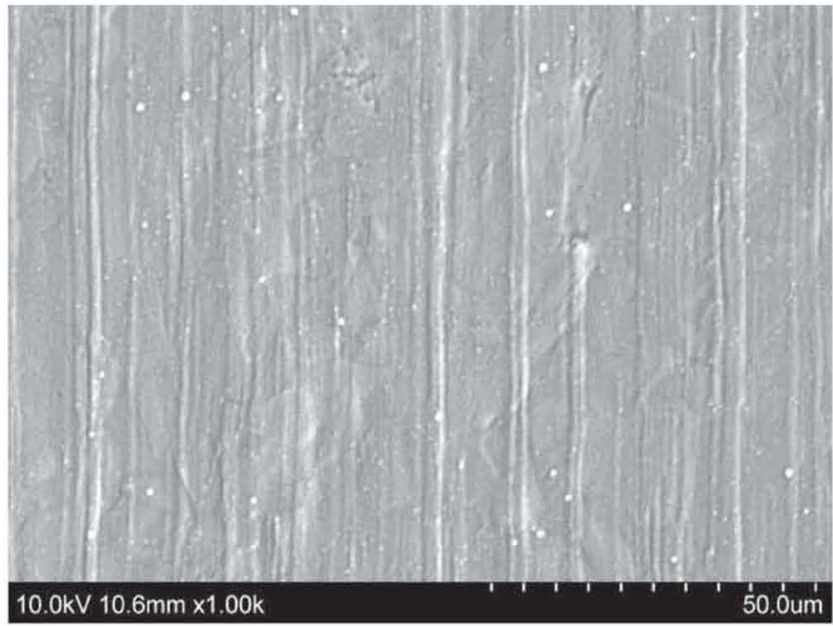

E

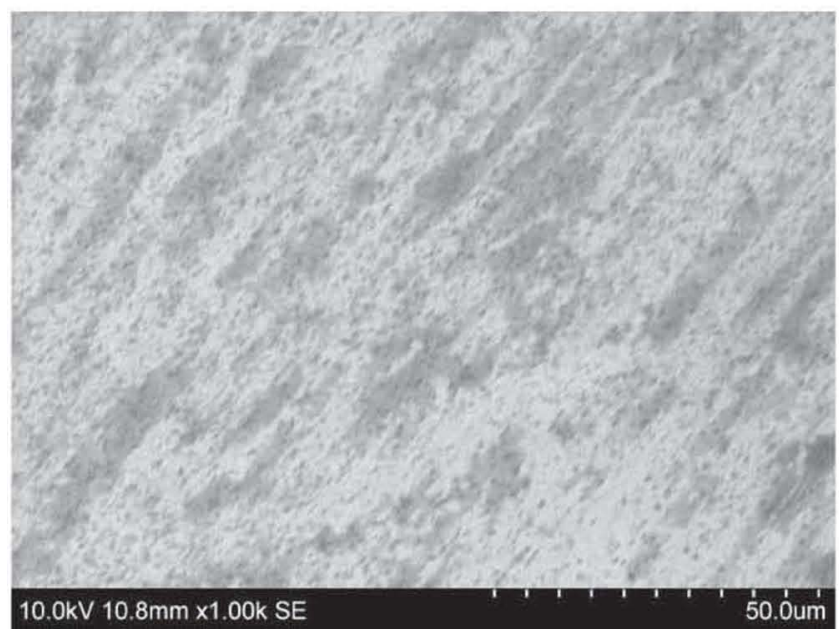

B

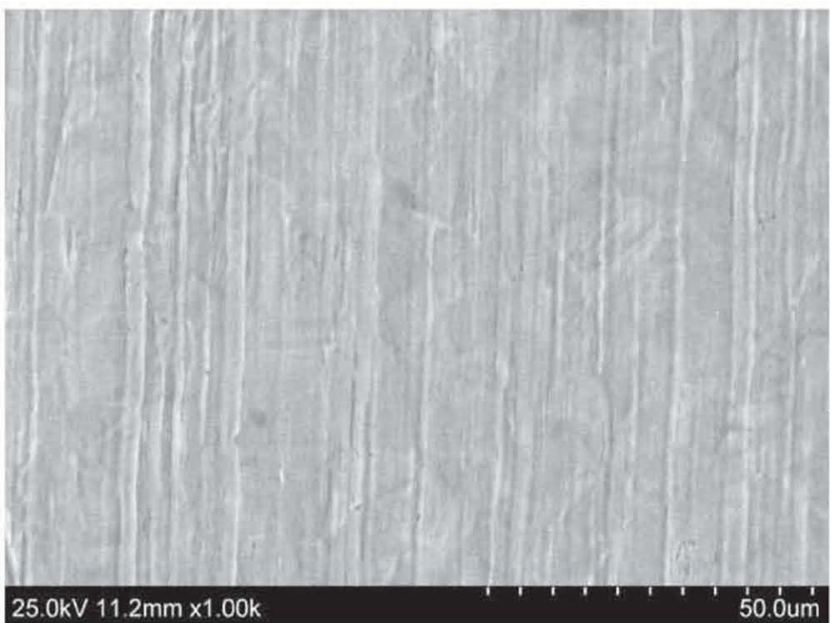

D

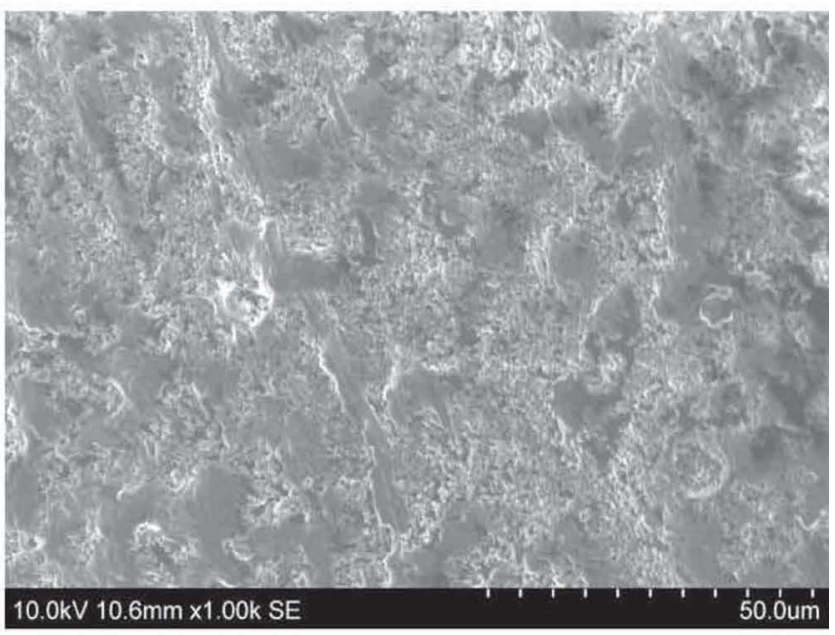

Figure 5. Scanning electron micrographs of (A) a native stainless steel (SS) coupon; (B) modified coupon AMC 18 (Advanced Materials Components Express, Lemont, PA); (C) modified coupon Dursan (SilcoTek Corporation, Bellefonte, PA); (D) modified coupon Lectrofluor 641 (General Magnaplate Corporation, Linden, NJ); and (E) modified coupon Ni-P-PTFE (Avtec Finishing Systems, New Hope, MN) at 1,000× magnification before biofilm formation. 
A

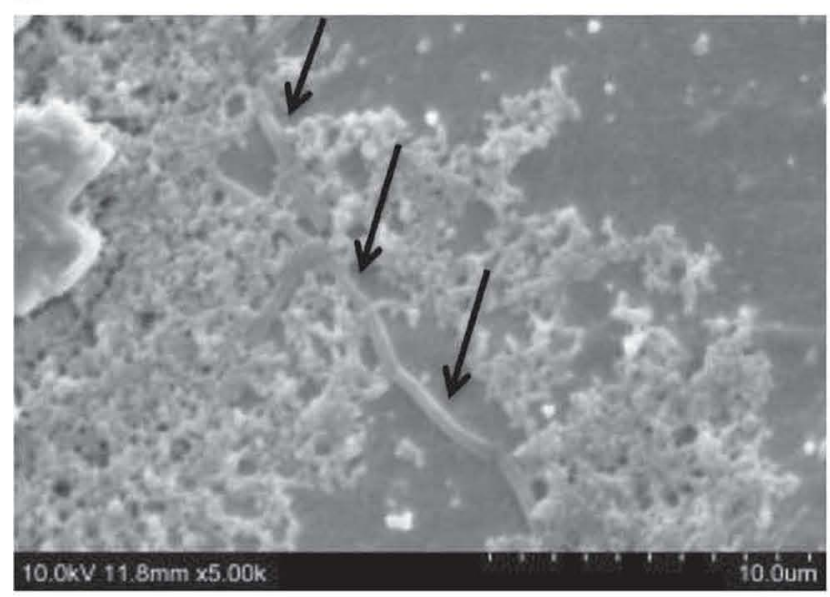

C

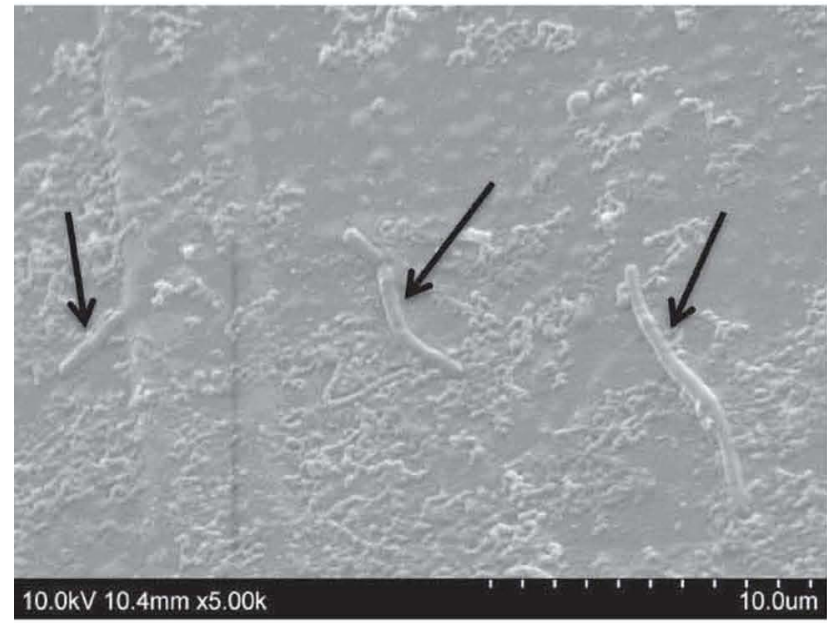

B

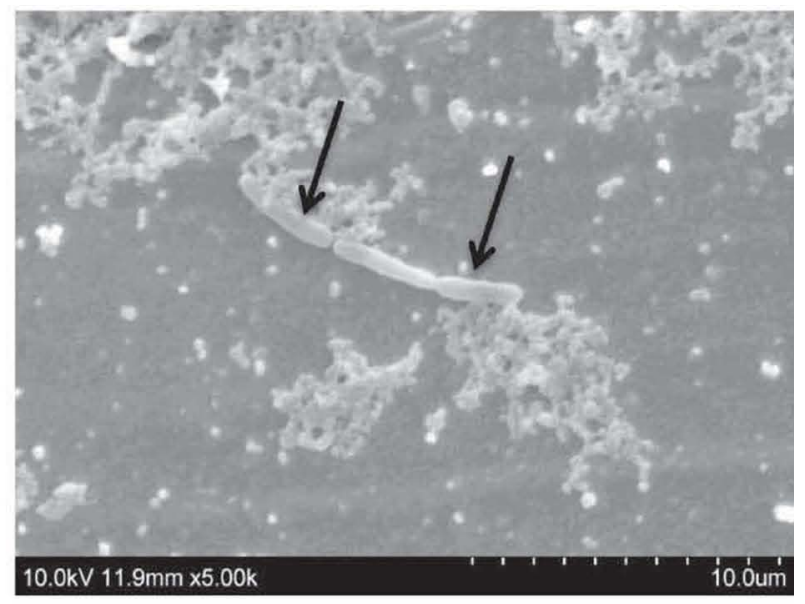

D

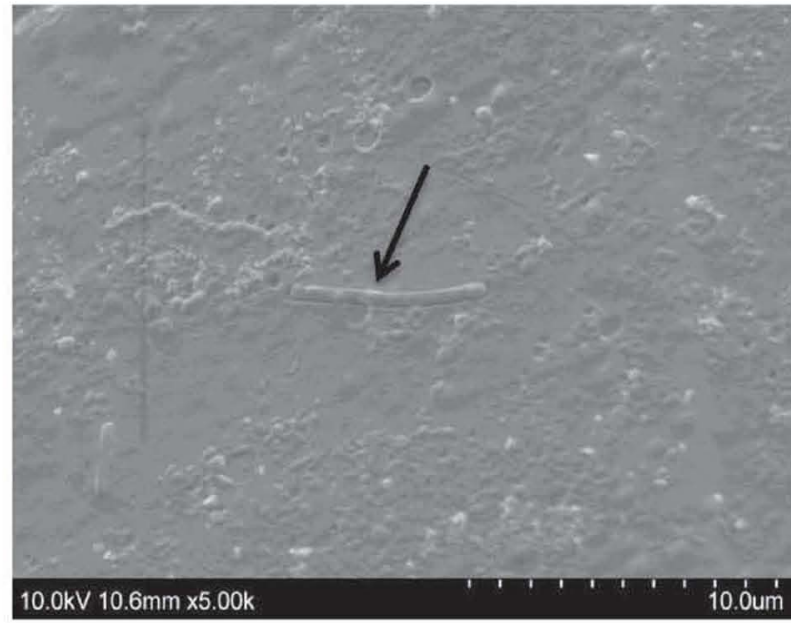

E

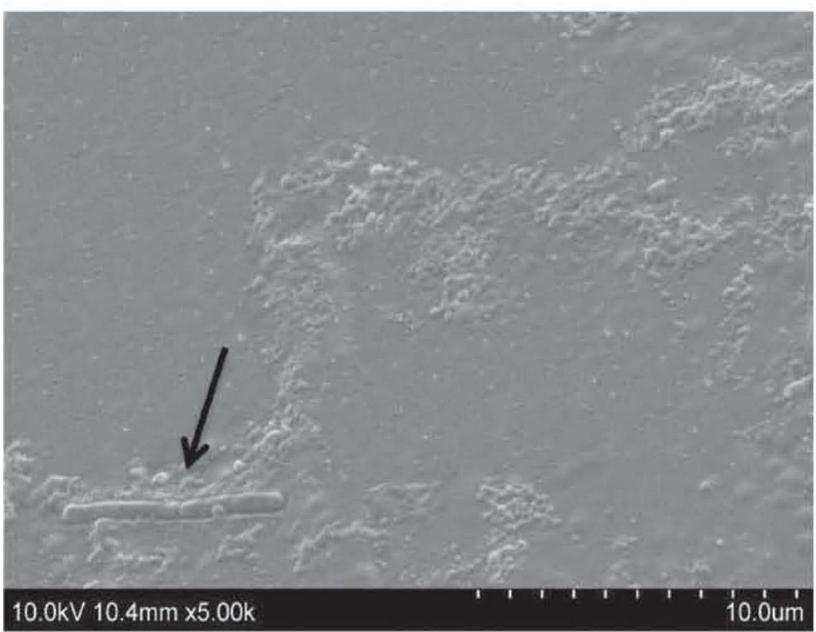

Figure 6. Scanning electron micrographs of (A) a native stainless steel (SS) coupon; (B) modified SS coupon AMC 18 (Advanced Materials Components Express, Lemont, PA); (C) modified SS coupon Dursan (SilcoTek Corporation, Bellefonte, PA); (D) modified SS coupon Lectrofluor 641 (General Magnaplate Corporation, Linden, NJ); and (E) modified SS coupon Ni-P-polytetrafluoroethylene (Avtec Finishing Systems, New Hope, MN) at 5,000× magnification after biofilm formation showing attachment of Geobacillus stearothermophilus and absorption of foulants on the surface. Black arrow shows the location of rods of G. stearothermophilus in the biofilm formed over SS coupons. 
and bacterial adhesion studies under laboratory conditions for academic purposes only.

\section{REFERENCES}

Baier, R. E. 2006. Surface behaviour of biomaterials: The theta surface for biocompatibility. J. Mater. Sci. Mater. Med. 17:1057-1062.

Barish, J. A., and J. M. Goddard. 2013. Anti-fouling surface modified stainless steel for food processing. Food Bioprod. Process. 91:352-361.

Barish, J. A., and J. M. Goddard. 2014. Stability of nonfouling stainless steel heat exchanger plates against commercial cleaning agents. J. Food Eng. 124:143-151.

Barnes, L.-M., M. Lo, M. Adams, and A. Chamberlain. 1999. Effect of milk proteins on adhesion of bacteria to stainless steel surfaces. Appl. Environ. Microbiol. 65:4543-4548.

Bhushan, B., and Y. C. Jung. 2007. Wetting study of patterned surfaces for superhydrophobicity. Ultramicroscopy 107:1033-1041.

Bryers, J. D. 1987. Biologically active surfaces: Processes governing the formation and persistence of biofilms. Biotechnol. Prog. 3:57-68.

Dexter, S. C. 1979. Influence of substratum critical surface tension on bacterial adhesion-In situ studies. J. Colloid Interface Sci. 70:346-354.

Downes, F. P., and K. Ito. 2001. Compendium of Methods for the Microbiological Examination of Foods (4th ed.). American Public Health Association, Washington, DC.

Doyle, C. J., D. Gleeson, K. Jordan, T. P. Beresford, R. P. Ross, G. F. Fitzgerald, and P. D. Cotter. 2015. Anaerobic sporeformers and their significance with respect to milk and dairy products. Int. J. Food Microbiol. 197:77-87.

Fletcher, M., and G. Loeb. 1979. Influence of substratum characteristics on the attachment of a marine pseudomonad to solid surfaces. Appl. Environ. Microbiol. 37:67-72.

Flint, S., J. Brooks, and P. Bremer. 2000. Properties of the stainless steel substrate, influencing the adhesion of thermo-resistant streptococci. J. Food Eng. 43:235-242.

Flint, S., J. Palmer, K. Bloemen, J. Brooks, and R. Crawford. 2001. The growth of Bacillus stearothermophilus on stainless steel. J. Appl. Microbiol. 90:151-157.

Hassan, A. N., S. Anand, and M. Avadhanula. 2010. Microscopic observation of multispecies biofilm of various structures on whey concentration membranes. J. Dairy Sci. 93:2321-2329.

Hinton, A., K. Trinh, J. Brooks, and G. Manderson. 2002. Thermophile survival in milk fouling and on stainless steel during cleaning. Food Bioprod. Process. 80:299-304.

Hoffman, W. 1983. CIP of straight pipes as a function of surface roughness and other factors. Dissertationzur Erlanguang des Doktorgrades der Agrarwissenschaftlichen Fakultat der ChristianAbrechis-Universitat, Keil.

Khanal, S. N., S. Anand, K. Muthukumarappan, and M. Huegli. 2014. Inactivation of thermoduric aerobic sporeformers in milk by ultrasonication. Food Contr. 37:232-239.

Klijn, N., L. Herman, L. Langeveld, M. Vaerewijck, A. A. Wagendorp, I. Huemer, and A. H. Weerkamp. 1997. Genotypical and phenotypical characterization of Bacillus sporothermodurans strains, surviving UHT sterilisation. Int. Dairy J. 7:421-428.
Langeveld, L., A. Bolle, and J. Vegter. 1972. Cleanability of stainless steel with different degrees of surface roughness. Neth. Milk Dairy J. 26:149-154

Liu, Y., W. Wu, G. Sethuraman, and G. Nancollas. 1997. Intergrowth of calcium phosphates: An interfacial energy approach. J. Cryst. Growth 174:386-392.

Lücking, G., M. Stoeckel, Z. Atamer, J. Hinrichs, and M. EhlingSchulz. 2013. Characterization of aerobic spore-forming bacteria associated with industrial dairy processing environments and product spoilage. Int. J. Food Microbiol. 166:270-279.

Mafu, A. A., D. Roy, J. Goulet, and P. Magny. 1990. Attachment of Listeria monocytogenes to stainless steel, glass, polypropylene, and rubber surfaces after short contact times. J. Food Prot. 53:742746.

Masurovsky, E., and W. Jordan. 1958. Studies on the relative bacterial cleanability of milk-contact surfaces. J. Dairy Sci. 41:1342-1358.

Murphy, P. M., D. Lynch, and P. M. Kelly. 1999. Growth of thermophilic spore forming bacilli in milk during the manufacture of low heat powders. Int. J. Dairy Technol. 52:45-50.

Pedersen, K. 1990. Biofilm development on stainless steel and PVC surfaces in drinking water. Water Res. 24:239-243.

Perry, S. F. 1995. Freeze-drying and cryopreservation of bacteria. Methods Mol. Biol. 38:21-30.

Pringle, J. H., and M. Fletcher. 1983. Influence of substratum wettability on attachment of freshwater bacteria to solid surfaces. Appl. Environ. Microbiol. 45:811-817.

Rönner, U., U. Husmark, and A. Henriksson. 1990. Adhesion of $\mathrm{Ba}$ cillus spores in relation to hydrophobicity. J. Appl. Bacteriol. 69:550-556.

Rosmaninho, R., and L. F. Melo. 2006. Calcium phosphate deposition from simulated milk ultrafiltrate on different stainless steel-based surfaces. Int. Dairy J. 16:81-87.

Rosmaninho, R., O. Santos, T. Nylander, M. Paulsson, M. Beuf, T. Benezech, S. Yiantsios, N. Andritsos, A. Karabelas, and G. Rizzo. 2007. Modified stainless steel surfaces targeted to reduce fouling-Evaluation of fouling by milk components. J. Food Eng. 80:1176-1187.

Sandu, C., and R. Singh. 1991. Energy increase in operation and cleaning due to heat-exchanger fouling in milk pasteurization. Food Technol. 45:84-91.

Schmidt, D. L., R. F. Brady, K. Lam, D. C. Schmidt, and M. K. Chaudhury. 2004. Contact angle hysteresis, adhesion, and marine biofouling. Langmuir 20:2830-2836.

Tide, C., S. R. Harkin, G. G. Geesey, P. J. Bremer, and W. Scholz. 1999. The influence of welding procedures on bacterial colonization of stainless steel weldments. J. Food Eng. 42:85-96.

Tsibouklis, J., M. Stone, A. A. Thorpe, P. Graham, T. G. Nevell, and R. J. Ewen. 2000. Inhibiting bacterial adhesion onto surfaces: The non-stick coating approach. Int. J. Adhes. Adhes. 20:91-96.

Vanhaecke, E., J. Remon, M. Moors, F. Raes, D. De Rudder, and A. Van Peteghem. 1990. Kinetics of Pseudomonas aeruginosa adhesion to 304 and 316-L stainless steel: Role of cell surface hydrophobicity. Appl. Environ. Microbiol. 56:788-795.

Wehr, H. M., and J. F. Frank. 2004. Standard methods for the examination of dairy products (17th ed.). American Public Health Association, Washington, DC.

Zhao, Q. 2004. Effect of surface free energy of graded Ni-P-PTFE coatings on bacterial adhesion. Surf. Coat. Tech. 185:199-204. 